\title{
Analisis Variasi Temperatur Aktivasi terhadap Gugus Fungsi Arang Aktif Tandan Aren (Arenga Pinnata Merr.) dengan Agen Aktivasi Potassium Silicate $\left(\mathrm{K}_{2} \mathrm{SiO}_{3}\right)$
}

\author{
Nandini Nur Hijrah ${ }^{1 *}$, Muhammad Anas ${ }^{2)}$, Erniwati ${ }^{2)}$ \\ 1)* Mahasiswa Jurusan Pendidikan Fisika FKIP UHO, Kendari, \\ ${ }^{2)}$ Dosen Jurusan Pendidikan Fisika FKIP UHO, Kendari \\ *Korespondensi Email: nandininurhijrah@gmail.com
}

\begin{abstract}
Abstrak: Penelitian ini bertujuan untuk mengetahui bagaimana efek variasi temperatur aktivasi terhadap gugus fungsi arang aktif dari limbah tandan aren (Arengga Pinnata Merr) dengan agen aktivasi potassium silicate $\left(\mathrm{K}_{2} \mathrm{SiO}_{3}\right)$. Proses pembuatan arang aktif dibagi menjadi tiga tahap yaitu tahap persiapan menyiapkan tandan aren kemudian dipotong, dicuci dan dijemur, tahap karbonasi pada suhu $300^{\circ} \mathrm{C}-400^{\circ} \mathrm{C}$ selama \pm 8 jam dan tahap aktivasi kimia-fisika. Potassium silicate $\mathrm{K}_{2} \mathrm{SiO}_{3}$ merupakan agen aktivasi baru yang digunakan untuk mengaktifkan arang aktif dengan menggunakan perbandingan $2: 1\left(\mathrm{~K}_{2} \mathrm{SiO}_{3}\right.$ : arang aktif tandan aren) selama 12 jam dan suhu aktivasi $600^{\circ} \mathrm{C}, 650^{\circ} \mathrm{C}, 700^{\circ} \mathrm{C}, 750^{\circ} \mathrm{C}$ dan $800^{\circ} \mathrm{C}$ selama 30 menit. Karakterisasi arang aktif tandan aren diuji menggunakan Fourier Transform Infrared (FTIR). Spektrum FTIR menunjukkan arang aktif yang dihasilkan memiliki pola serapan dengan jenis ikatan $\mathrm{C} \equiv \mathrm{C}$ (Alkuna), $\mathrm{C}=\mathrm{C}$ (Cincin Aromatik), C-H (Alkana), Si-O dan C-H (Alkana). Diperoleh informasi bahwa temperatur aktivasi yang baik untuk arang aktif tandan aren terlihat pada temperatur $700{ }^{\circ} \mathrm{C}$ dan $750{ }^{\circ} \mathrm{C}$ dengan serapan IR terbesar terlihat pada temperatur $800^{\circ} \mathrm{C}$.
\end{abstract}

Kata Kunci: Arang Aktif; Potassium Silicate; Temperatur Aktivasi; Gugus Fungsi

Abstract: This study aims to determine the effect of variations of the sugar palm activation temperature on the functional groups of activated charcoal from palm bunch (Arengga Pinnata Merr) with potassium silicate $\left(\mathrm{K}_{2} \mathrm{SiO}_{3}\right)$ activation agent. The process of making an chemically activated charcoal is divided into three stages, firstly the preparation stage of preparing the palm bunches into cutting, washing and drying, secondly carbonitation stage at a temperature of $300^{\circ} \mathrm{C}-400^{\circ} \mathrm{C}$ about \pm 8 hours and the chemical activation stage. Potassium silicate $\mathrm{K}_{2} \mathrm{SiO}_{3}$ is a new activation agent that is used to activate an activated charcoal by using 2: 1 ratio $\left(\mathrm{K}_{2} \mathrm{SiO}_{3}\right.$ : activated palm bunches) for 12 hours and an activation temperature of $600^{\circ} \mathrm{C}$, $650^{\circ} \mathrm{C}, 700^{\circ} \mathrm{C}, 750^{\circ} \mathrm{C}$, and $800^{\circ} \mathrm{C}$ for 30 minutes. Characterization of activated charcoal from palm bunches was tested by using Fourier Transform Infrared (FTIR). The FTIR spectrum shows that the activated charcoal produced has an absorption pattern with the types of bonds are $C \equiv C$ (Alkuna), $C=C$ (Aromatic Rings), $C-H$ (Alkanes), Si-O and $C-H$ (Alkanes). The Information was obtained that a good activation temperature for activated charcoal of palm bunches was seen at temperatures of $650^{\circ} \mathrm{C}, 700^{\circ} \mathrm{C}$ and $750^{\circ} \mathrm{C}$ with the largest IR absorption was seen at temperatures of $700^{\circ} \mathrm{C}$.

Keywords: Activated Charcoal; Potassium Silicate; Activation Temperature; Functional Groups.

\section{PENDAHULUAN}

Pohon aren (Arenga pinnata Merr.) merupakan jenis tanaman yang tumbuh sangat melimpah di Indonesia. Tanaman ini termasuk dalam kelompok famili Arecaceae yang dapat tumbuh subur didaerah yang memiliki curah hujan yang tinggi dan merata sepanjang tahun (Ansar, 2019). Hampir semua bagian maupun pohon aren bermanfaat dan dapat digunakan untuk berbagai kebutuhan, baik bagian fisik (daun, batang, ijuk, akar, dll.) maupun bagian produksinya (buah, nira dan pati/tepung) (Lempang, 2012). Salah satu bagian tanaman aren yang menyisakan limbah padatan setelah melalui pengolahan adalah tandan aren. Padahal limbah dari tandan aren memiliki kandungan yang dapat diolah sebagai bahan baku arang aktif. Jasmal (2015) dalam penelitiannya menyebutkan bahwa bahan baku yang dapat dibuat menjadi arang aktif adalah semua 
bahan yang mengandung lignoselulosa (lignin dan selulosa), baik yang berasal dari tumbuhtumbuhan maupun dari binatang. Sedangkan Sumaiyah (2016) menyebutkan bahwa limbah tandan aren memiliki kandungan senyawa kimia diantarnya adalah $27,74 \%$ lignin, $68,11 \%$ homiselulosa, 33,79\% $\alpha$-selulosa, 11,10\% kadar air dan $1,80 \%$ ekstraktif. Berdasarkan hal tersebut maka limbah tandan aren dapat dimanfaatkan sebagai bahan pembuatan karbon aktif atau arang aktif.

Data di atas menunjukkan bahwa limbah tandan aren dapat diolah dan dimanfaatkan sebagai bahan karbon aktif. Karbon aktif dari limbah tandan aren telah diketahui nilai daya serap dengan kapasitas adsorbsi iodium sebesar $364,43 \mathrm{mg} / \mathrm{g}$ dan metilen blue sebesar $67,84 \mathrm{mg} / \mathrm{g}$ pada temperatur $700^{\circ} \mathrm{C}$ (Sari, 2019), dengan struktur kristal berbentuk heksagonal terbentuk disemua variasi suhu (Mongkito, et.al 2019). Serta gugus fungsi hasil analisis FTIR menunjukkan bahwa adanya ikatan gugus fungsi karbon selain itu juga teridentifikasi gugus $\mathrm{C}-\mathrm{O}$ dan $\mathrm{C}-\mathrm{H}$ yang cenderung bersifat lebih polar (Irmawati, 2019). Berdasarkan hasil penelitian tersebut, arang aktif dari limbah tandan aren memiliki daya serap yang belum sesuai dengan standarisasi karbon aktif (SNI-06-3730-1995) yang telah ditetapkan yaitu untuk $\mathrm{I}_{2}$ sebesar $750 \mathrm{mg} / \mathrm{g}$ dan metilen blue sebesar $120 \mathrm{mg} / \mathrm{g}$. Preparasi sampel arang aktif dari tandan aren dilakukan dengan memvariasikan temperatur aktivasi $\left(600^{\circ} \mathrm{C}, 650^{\circ} \mathrm{C}\right.$, $700^{\circ} \mathrm{C}, \quad 750^{\circ} \mathrm{C}, \quad 800^{\circ} \mathrm{C}$ dan $\left.850^{\circ} \mathrm{C}\right)$ kemudian dilakukan analisis.

Arang aktif tidak hanya memiliki atom karbon, tetapi juga memiliki ikatan kimia dalam bentuk gugus fungsi. Gugus fungsi ini menjadikan permukaan karbon aktif reaktif secara kimia dan dapat mempengaruhi sifat adsorbsinya (Murti, 2008). Kualitas arang aktif dipengaruhi oleh beberapa faktor diantarnya yaitu kualitas bahan baku, suhu atau temperatur serta waktu aktivasi. Selain itu untuk meningkatkan kualitas karbon aktif beberapa penelitian terbaru juga menambahkan aktivator kimia. Agen aktivasi ini berperan sebagai dehydrating agent yang akan mempengaruhi dekomposisi pirolisis, menghambat pembentukan tar, dan mengurangi pembentukan asam asetat, metanol, dan lain-lain. Mentari, et.al (2018) menyebutkan gugus fungsi arang aktif kelapa sawit yang teraktivasi asam nitrat $\left(\mathrm{HNO}_{3}\right)$ menunjukan hasil analisa FTIR yaitu adanya gugus $\mathrm{C}=\mathrm{O}, \mathrm{C}=\mathrm{C}$, C-C, N=O, C-N, C-OH, $\mathrm{CH}_{2}$ dan CH. Sedangkan Kong, et.al (2014) melaporkan hasil penelitiannya mengenai arang aktif dari limbah kulit binatang (CW) dan bahan lignoselulosa (CA) yang di aktivasi menggunakan kalium silikat $\left(\mathrm{K}_{2} \mathrm{SiO}_{3}\right)$ menunjukkan hasil analisis FTIR yaitu adanya kelompok fungsional yang mengandung karbon seperti $\mathrm{CO}$ (anhidridha, karbokshilat atau ester/keton) pada bilangan gelombang $3428 \mathrm{~cm}^{-1}$, C-OH atau C-O-C (fenol/ester/amida/anhidrida) pada bilangan gelombang 1624,21 $\mathrm{cm}^{-1}$. Dibandinga CA, CW menunjukkan tingginya kandungan gugus fungsional oksigen. Namun, setelah proses aktivasi gugus fungsi $\mathrm{C}$ semakin meningkat.

Penelitian sebelumnya telah meneliti mengenai pembuatan arang aktif dari tandan aren dengan memvariasikan temperatur aktivasi Mongkito, et.al (2019) Irmawati (2019). Pada penelitian ini, sebelum arang tandan aren diaktivasi fisika terlebih dahulu diaktivasi menggunakan agen Potassium Silicate $\left(\mathrm{K}_{2} \mathrm{SiO}_{3}\right)$.

\section{METODE}

Penelitian ini termasuk dalam jenis penelitian fisika eksperimen dengan bidang kajian fisika material. Pelaksanaan penelitian dimulai dari bulan November 2019 - selesai. Pengambilan bahan baku sampel limbah tandan aren berada di Desa Lantowunua, Kecamatan Rumbia, Kabupaten Bombana, Kota Kendari, Provinsi Sulawesi Tenggara. Aktivasi kimia dan aktivasi fisika arang limbah tandan aren dilakukan di Laboratorium Jurusan Pendidikan Kimia Universitas Universitas Halu Oleo

Tahapan pembuatan arang tandan aren mengacu pada penelitian Irmawati (2019). Sedangkan aktivasi kimia menggunakan larutan potassium silicate $\left(\mathrm{K}_{2} \mathrm{SiO}_{3}\right)$ dengan perbandingan 2:1 $\left(\mathrm{g} \mathrm{K}_{2} \mathrm{SiO}_{3}\right.$ : g arang aktif tandan aren) mengacu pada penelitian Kong, et.al (2014) dan aktivasi fisika dilakukan dengan menggunakan tanur listrik dengan memberikan variasi temperatur aktivasi $\left(600^{\circ} \mathrm{C}\right.$, $650^{\circ} \mathrm{C}, 700^{\circ} \mathrm{C}, 750^{\circ} \mathrm{C}$ dan $800^{\circ} \mathrm{C}$ ) selama 30 menit. Setelah di aktivasi fisika arang aktif direndam dengan menggunakan air panas kemudian arang aktif dikeringkan menggunakan oven selama 8 jam pada temperatur $105^{\circ} \mathrm{C}$. Larutan potasium silicate diperoleh di toko lokal Kota Makassar Provinsi Sulawesi Selatan. Identifikasi gugus fungsi yang muncul dari arang aktif tandan aren yang telah divariasikan temperatur aktivasinya dengan menggunakan analisis FTIR (fourier transform infrared) yang dilakukan di Laboratorium Fisika 
Material, Institut Teknologi Sepuluh November HASIL DAN PEMBAHASAN (ITS), Surabaya.

1. Spektrum IR Arang Aktif Tandan Aren

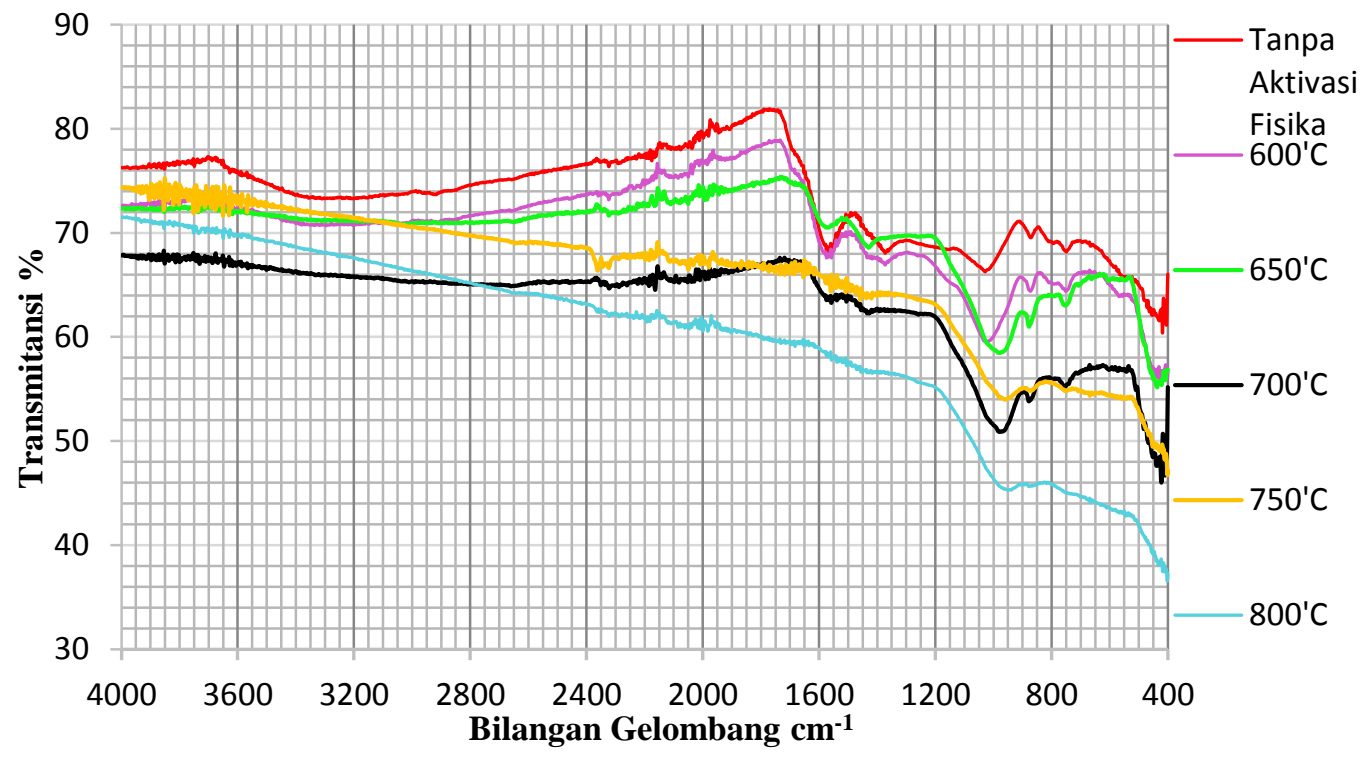

Gambar 1. Spektrum IR Arang Aktif Teraktivasi Potassium Silicate $\left(\mathrm{K}_{2} \mathrm{SiO}_{3}\right)$ dan Arang Aktif dengan Dua Aktivasi.

Gambar 4.1 memperlihatkan hubungan antara bilangan gelombang dan banyaknya transmisi IR arang aktif tanfan aren pada beberapa temperatur. Arang Aktif teraktivasi $\mathrm{K}_{2} \mathrm{SiO}_{3}$ menunjukkan serapan terdapat yang pada bilangan gelombang $430,23 \mathrm{~cm}^{-1}, 749,57 \mathrm{~cm}^{-1}, 1029,26 \mathrm{~cm}^{-1}, 1574,48 \mathrm{~cm}^{-}$
${ }^{1}, 3310,05 \mathrm{~cm}^{-1}$ yang diidentifikasi sebagai vibrasi dari gugus $\mathrm{C}-\mathrm{H}$ (alkana), $\mathrm{C}-\mathrm{H}$ (alkena), $\mathrm{Si}-\mathrm{O}, \mathrm{C}=\mathrm{C}$ (cincin aromatik) dan $\mathrm{O}-\mathrm{H}$ (alkohol). Gugus fungsi arang aktif tandan aren dengan berbagai variasi temperatur aktivasi secara berturut-turut dirangkum pada Tabel 1 berikut.

Tabel 1. Bilangan Gelombang dan Gugus Fungsi Arang Aktif Tandan Aren

\begin{tabular}{|c|c|c|c|c|c|c|}
\hline \multirow{2}{*}{$\begin{array}{c}\text { Temperatur } \\
\text { Aktivasi } \\
\text { Tanpa aktivasi } \\
\text { fisika }\end{array}$} & \multicolumn{6}{|c|}{ Bilangan Gelombang $\left(\mathrm{cm}^{-1}\right)$} \\
\hline & 430,23 & 749,57 & 1029,26 & 1574,48 & - & 3310,05 \\
\hline $600^{\circ} \mathrm{C}$ & 434,10 & 751,18 & 1026,58 & 1574,33 & - & 3295,75 \\
\hline $650^{\circ} \mathrm{C}$ & 436,96 & 753,21 & 977,37 & 1575,48 & 2323,46 & 3030,76 \\
\hline $700^{\circ} \mathrm{C}$ & 437,69 & 754,39 & 979,96 & 1557,82 & 2322,52 & - \\
\hline $750^{\circ} \mathrm{C}$ & - & - & 961,22 & 1559,68 & 2361,89 & - \\
\hline $800^{\circ} \mathrm{C}$ & - & - & 960,42 & - & - & - \\
\hline Gugus fungsi & $\begin{array}{c}\text { C-H } \\
\text { (Alkana) }\end{array}$ & $\begin{array}{c}\text { C-H } \\
\text { (Alkena) }\end{array}$ & $\mathrm{Si}-\mathrm{O}$ & $\begin{array}{c}\mathrm{C}=\mathrm{C}(\text { Cincin } \\
\text { Aromatik) }\end{array}$ & $\begin{array}{c}\mathrm{C} \equiv \mathrm{C} \\
\text { (Alkuna) }\end{array}$ & OH (Alkohol) \\
\hline Referensi & $\begin{array}{c}\text { Nasution } \\
\text { dan Rambe, } \\
2013\end{array}$ & $\begin{array}{l}\text { Wardani } \\
\text { dan } \\
\text { Rosa, } \\
2018\end{array}$ & $\begin{array}{c}\text { Kong, dkk, } \\
2014\end{array}$ & $\begin{array}{c}\text { Setiawan, dkk, } \\
2017\end{array}$ & $\begin{array}{l}\text { Nasution } \\
\text { dan } \\
\text { Rambe, } \\
2013\end{array}$ & Zein, dkk, 2019 \\
\hline
\end{tabular}

Gugus fungsi C-H (alkana) yang terbentuk pada bilangan gelombang $430,23 \mathrm{~cm}^{-1}$ sedikit bergeser kearah bilangan gelombang yang lebih tinggi seiring dengan naiknya temperatur aktivasi. Namun demikian, gugus ini tidak muncul pada temperatur di atas $700^{\circ} \mathrm{C}$. Gugus $\mathrm{C}-\mathrm{H}$ (alkena) yang terbentuk pada bilangan gelombang $749,57 \mathrm{~cm}^{-1}$ dan semakin bergeser ke arah bilangan gelombang yang semakin 
besar seiring dengan meningkatnya temperatur aktivasi. Tetapi gugus fungsi ini tidak muncul pada temperatur $750^{\circ} \mathrm{C}$ dan $800^{\circ} \mathrm{C}$. Hal ini dikarenakan kenaikan temperatur aktivasi menyebabkan gugus $\mathrm{C}$ $\mathrm{H}$ (alkana) dan C-H (alkena) terurai. Dimana unsur $\mathrm{H}$ menguap dengan akan menguap seiring dengan naiknya temperatur aktivasi sementara unsur $\mathrm{C}$ bergabung dan membentuk ikatan rangkat karbon.

Serapan pada bilangan gelombang $1029,26 \mathrm{~cm}^{-}$ ${ }^{1}$ diidentifikasi sebagai gugus $\mathrm{Si}-\mathrm{O}$ yang muncul di semua temperatur aktivasi namun terjadi pergeseran bilangan gelombang. Munculnya pola serapan $\mathrm{Si}-\mathrm{O}$ disebabkan oleh bahan yang diaktifkan dari senyawa $\mathrm{K}_{2} \mathrm{SiO}_{3}$ yang digunakan (Kong, et.al., 2014). Semakin tinggi temperatur aktivasi menyebabkan beberapa gugus fungsi muncul atau hilang hanya pada temperatur tertentu. Karena meningkatnya temperatur aktivasi akan mengakibatkan perubahan gugus fungsi yaitu terjadinya pergeseran, hilangnya bilangan gelombang serapan atau tingkat serapannya berkurang dan terbentuknya senyawa radikal tidak stabil yang selanjutnya bereaksi membentuk senyawa baru (Wibowo et al., 2011). Dapat dilihat pada tabel 4.1 gugus $\mathrm{Si}-\mathrm{O}$ tetap mucul baik pada arang teraktivasi $\mathrm{K}_{2} \mathrm{SiO}_{3}$ maupun arang aktif (semua temperatur aktivasi). Dimana ketika temperatur aktivasi semakin tinggi bilangan gelombang yang muncul menggeser ke bilangan gelombang yang lebih kecil. Hal ini dikarenakan kenaikan temperatur aktivasi menyebabkan unsur $\mathrm{O}$ semakin berkurang sedangkan unsur Si ketika dipanaskan akan semakin kuat sehingga akan menyebabkan terjadinya pergeseran bilangan gelombang kearah yang lebih kecil.

Hasil analisis FTIR juga mengidentifikasi munculnya ikatan $\mathrm{C}=\mathrm{C}$ aromatik di sekitar panjang gelombang $1559 \mathrm{~cm}^{-1}-1576 \mathrm{~cm}^{-1}$ pada arang aktif teraktivasi $\mathrm{K}_{2} \mathrm{SiO}_{3}$ dan pada temperatur aktivasi $600^{\circ} \mathrm{C}, \quad 650^{\circ} \mathrm{C}, \quad 700^{\circ} \mathrm{C}$ dan $750^{\circ} \mathrm{C}$ hal ini membuktikan bahwa proses karbonisasi dan aktivasi menjadi arang aktif akan meningkatkan senyawa aromatik. Senyawa tersebut merupakan penyusun struktur heksagonal arang dan arang aktif (Wibowo et al., 2011). Temperatur aktivasi yang semakin tinggi akan makin menguatkan gugus aromatik (Yusran, 2014). Peningkatan temperatur aktivasi juga mengakibatkan terbentuknya serapan baru pada bilangan gelombang 2323,46 $\mathrm{cm}^{-1}$ yang diidentifikasi sebagai gugus $\mathrm{C} \equiv \mathrm{C}$ (Alkuna) pada temperatur $650^{\circ} \mathrm{C}, 700^{\circ} \mathrm{C}$ dan $750^{\circ} \mathrm{C}$ menunjukkan bahwa proses karbonasi dan aktivasi akan meningkatkan ikatan gugus karbon sekaligus menunjukkan bahwa arang aktif tandan aren dengan aktivasi kimia-fisika mengandung karbon yang tinggi (Yusran, 2016). Peran $\mathrm{K}_{2} \mathrm{SiO}_{3}$ juga meningkatkan terbentuknya gugus fungsi yang mengandung karbon (Kong, et.al., 2014). Gugus $\mathrm{C}=\mathrm{C}$ dan $\mathrm{C} \equiv \mathrm{C}$ (Alkuna) adalah gugus berupa karbon dengan jumlah kemurnian yang tinggi, dimana terjadi pelepasan unsur $\mathrm{O}$ dan $\mathrm{H}$ yang awalnya menyatu dengan unsur $\mathrm{C}$. Ikatan rangkap karbon juga mengindikasi semakin murninya unsur karbon yang dihasilkan (Nasution dan Rambe, 2013). Peningkatan temperatur aktivasi juga menyebabkan abu yang terbentuk semakin banyak, unsur karbon akan lebih banyak terbakar sehingga pori-pori akan mengalami kerusakan berlebih sehingga menghasilkan penurunan luas permukaan (Shofa, 2012).

Selain ikatan gugus karbon, arang teraktivasi $\mathrm{K}_{2} \mathrm{SiO}_{3}$ dan arang aktif dengan aktivasi kimia-fisika menunjukkan masih adanya sisa uap air pada proses aktivasi arang aktif dan pada saat karbonasi arang untuk persiapan sampel, dengan teridentifikasinya gugus $\mathrm{OH}$ pada arang aktif. Gugus tersebut dapat berasal dari reaksi antara uap air dengan senyawa bebas pada permukaan arang yang diaktivasi. Munculnya ikatan $\mathrm{OH}$ dan $\mathrm{C}=\mathrm{O}$ menunjukkan bahwa arang aktif tandan aren yang dihasilkan cenderung bersifat lebih polar. Dengan demikian arang aktif yang dihasilkan dapat digunakan sebagai adsorben zat yang cenderung bersifat polar seperti penjernihan air, gula, alkohol atau sebagai penyerap formaldehid. Gambar 4.1 menunjukkan bahwa serapan IR terbesar muncul pada temperatur $800^{\circ} \mathrm{C}$ hal ini dikarenakan dari keseluruhan data yang diperoleh memiliki transmisi yang paling kecil dibandingkan pada temperatur lain (Dachriyanus, 2004). Secara keseluruhan dapat dikatakan bahwa meningkatnya temperatur aktivasi pada arang aktif tandan aren menyebabkan semakin sedikitnya gugus fungsi yang muncul. Hasil analisis FTIR yang baik terlihat pada temperatur $650^{\circ} \mathrm{C}, 700^{\circ} \mathrm{C}, 750^{\circ} \mathrm{C}$ yang mengidentifikasi adanya ikatan rangkap karbon.

\section{KESIMPULAN}

Berdasarkan hasil penelitian dan pembahasan dapat disimpulkan bahwa gugus fungsi Si-O yang terbentuk pada bilangan gelombang $1029 \mathrm{~cm}^{-1}-979$ $\mathrm{cm}^{-1}$ muncul disemua temperatur aktivasi sedangkan gugus fungsi $\mathrm{C}=\mathrm{C}$ (cincin aromatik) yang terbentuk pada bilangan gelombang $1574 \mathrm{~cm}^{-1}-1559 \mathrm{~cm}^{-1}$ tidak muncul pada temperatur $800^{\circ} \mathrm{C}$. 


\section{SARAN}

Saran yang dapat peniliti berikan untuk penelitian selanjutnya adalah perlu diadakannya penelitian gugus fungsi material arang aktif tandan aren menggunakan agen aktivasi lain dengan jenis larutan PA atau dengan mengubah perbandingan larutan dengan konsentrasi yang lebih kecil.

\section{DAFTAR PUSTAKA}

Ansar, Nazaruddin, \& Atri D A 2019. Pengaruh Suhu dan Lama Penyimpanan Terhadap Perubahan PH dan Warna Nira Aren (Arenga pinnata Merr) setelah Penyadapan, Vol. 8, No. 1, ISSN 2302-559X.

Irmawati, W 2019. Efek Variasi Temperatur Aktivasi Terhadap Gugus Fungsional Arang Aktif Tandan Aren ( Arenga Pinnata Merr.), Universitas Halu Oleo, Kendari.

Jasmal, Sulfikar \& Ramlawati 2015. Kapasitas Adsorpsi Arang Aktif Ijuk Pohon Aren (arenga pinnata) terhadap $\mathrm{Pb}^{2+}$, Jurnal Sainsmat, Vol. IV, No.1. ISSN 2086-6755.

DOI:

https://doi.org/10.35580/sainsmat4112842015

Kong, J, Qinyan, Y, Baoyu, G, Qian, L, Yan, W \& Huu, H N 2015. Comparative Study on Microstructure and Surface Properties of Keratin and Lognocellulosic Based Active Carbons, Shandong University, Cina. DOI:10.1016/j.fuproc.2015.08.025.

Kong, J, Qinyan, Y,Baoyu, G, Qian, L, Yan, W, Huu, H N \& Weshan, G 2014. Porous Sructure and Adsoptive Properties of Hide Waste Activated Carbon Prepared Via Potassium Silicate Activation, Shandong University, Cina. Vol.109

DOI:https://doi.org/10.1016/j.jaap.2014.06.012.

Lempang, M 2012. Pohon Aren dan Manfaat Produksinya, Info Teknis EBONI, Vol.9, No.1. DOI:https://doi.org/10.20886/buleboni.4993
Murti, S 2008. Pembuatan Karbon Aktif dari Tongkol Jagung untuk Adsorpsi Molekul Amonia dan Ion Krom, Universitas Indonesia, Depok.

Mongkito, V S R, Muhammad, A \& Wisda, P B. Investigating The Effect Activatoin Temperature on The Crystal Structure Od Activated Charcoal From Palm Bunches (Arenga Pinnata Merr.), Vol.2, No. 1. DOI:https://doi.org/10.12928/irip.v2i1.818.

Nasution Z A \& Rambe S M 2013. Karakterisasi dan Identifikasi Gugus Fungsi dari Karbon Cangkang Kelapa Sawit dengan Metode Methano Pyrolysis. Jurnal Dinamika Penelitian Industri, Vol. 24, No. 2. DOI:http://dx.doi.org/10.28959/jdpiv24i2.530.

Sari, A 2019. Analisis Daya Serap dan Metilen Blue Arang Aktif dari Tandan Aren (Arenga Pinnata), Universitas Halu Oleo, Kendari.

Sumaiyah, B W \& Karsono 2016. Utilizization of Microcrystalline Cellulose of Sugar Palm Bunches (Arenga Pinnata(Wurmb)Merr) as Excipients Tablet Direct Compression. Internasional Journal of Pharm Tech Reseacrh. Vol.9, No.7, ISSN:0974- 4304. DOI:http://repository.usu.ac.id/handle/1234567 $89 / 71044$.

Shofa 2012. Pembuatan Karbon Aktif Berbahan Baku Ampas Tebu dengan Aktivasi Kalium Hidroksida, Univeris tas Indonesia, Depok.

Skoog F, Douglas A, James H \& Timothy A N 1998. Prinsiple Of Instrumental Analysis. Saunders College Pub, Philadelphia.

Yusran, L 2018. Pengaruh Variasi Temperatur Aktivasi terhadap Gugus Fungsional Arang Aktif Cangkang Kelapa Sawit. Universitas Halu Oleo: Kendari. 